\title{
FATORES QUE PODEM INTERFERIR NA EVASÃO ESCOLAR EM UMA INSTITUIÇÃO DE ENSINO SUPERIOR PRIVADA
}

\author{
Rafaela Costa Silva* \\ Ana Flávia de Moraes Moraes** \\ Geraldo Vieira da Costa***
}

RESUMO: A evasão escolar no ensino superior é um problema internacional que afeta de forma direta nos resultados dos sistemas educacionais, e suas causas têm sido alvo de vários estudos visto que emergem tanto das instituições de ensino superior quanto dos próprios discentes e da sociedade onde estão inseridos. Partindo deste princípio, este estudo se destinou a fazer o levantamento de alguns dos fatores que podem levar os alunos do curso de Administração de uma instituição de ensino superior privada do Estado do Amazonas a evadir. Trata-se de uma pesquisa de campo realizada por meio de aplicação de questionários aos alunos e entrevistas com professores e o coordenador do curso, cujos dados foram tratados por meio das estratégias da estatística descritiva e da análise de conteúdo. A partir da análise dos questionários e das entrevistas foi constatado que o índice de evasão na instituição de ensino analisada poderá ser de $11,5 \%$, além de envolver diversos aspectos que estão condicionados inclusive às ações de gestão institucional, dependendo de adoção de medidas para o entendimento e o controle do processo.

PALAVRAS-CHAVE: Evasão discente; Ensino superior; Gestão acadêmica.

\section{FACTORS THAT MAY INTERFERE IN SCHOOL TRUANCY IN A PRIVATE-OWNED INSTITUTION OF HIGHER EDUCATION}

\begin{abstract}
Truancy in higher education is an international issue that directly affects results in educational system. Its causes have been the object of several studies affecting the institutions of higher education, students and society. Current analysis is a survey of some factors that may lead students of the Administration Course from a private faculty in the state of Amazonas to quit school. Field research was undertaken by questionnaires to students and interviews with professors and the
\end{abstract}

\footnotetext{
" Bacharela em Administração pela Universidade Federal do Amazonas (UFAM), Brasil.

E-mail: rcsilva.026@gmail.com

* Doutora em Administração pela Universidade Federal de Minas Gerais (UFMG), Brasil.

**** Doutor em Psicologia pela Universidade de São Paulo (USP), Brasil.
} 
course's coordinator. Data were subjected to descriptive statistics and content analysis. Results of questionnaires and interviews revealed that truancy may reach $11.5 \%$ and involves several aspects conditioned by institutional administration. They depend on the adoption of measures for the understanding and control of the process.

KEY WORDS: Students' truancy; Higher education; Academic administration.

\section{INTRODUÇÃO}

O mercado de instituições privadas de educação superior está iniciando um processo de consolidação, como já ocorreu em outras indústrias. Fusões e aquisições de instituições estão ocorrendo, formando-se conglomerados de instituições que possuem unidades de ensino em vários Estados do país. Formam-se assim redes de instituições distribuídas geograficamente e que na maioria dos casos possuem unidades autônomas que continuam com seus cursos e seus sistemas de gestão.

Entretanto, com o número crescente e desenfreado de instituições de ensino superior privado, o processo de ensino-aprendizagem parece que deixou de ser o foco principal destas instituições, este passou a ser administrativo-financeiro e pouco foi feito para reformular este quadro precário de ensino que por vezes aplicam metodologias tradicionais que não suprem as necessidades do alunado. Além de não possuir, em alguns casos, infraestrutura e preparos adequados para atender as necessidades de seus alunos que acabam por evadir (SILVA, 2014).

Na concepção de Silva Filho et al. (2007), a evasão escolar no ensino superior é um problema internacional que afeta o resultado dos sistemas educacionais. As perdas de estudantes que iniciam, mas não terminam seus cursos são tidos como desperdícios sociais, acadêmicos e econômicos. No setor público, são recursos públicos investidos sem o devido retorno. No setor privado, é uma importante perda de receitas. Em ambos os casos, a evasão é uma fonte de ociosidade de professores, funcionários, equipamentos e espaço físico.

É importante destacar que o simples ingresso no ensino superior não garante o êxito educacional do estudante, visto que as características desse nível 
de ensino são bem diferentes do ensino médio. Essa nova fase desperta no alunado certa insegurança quanto à nova carreira e exige mudanças significativas de hábitos. A ocorrência de decepções no que se refere à vida universitária, à estrutura e à metodologia do trabalho acadêmico e ao excesso de aulas teóricas nos primeiros semestres acaba, em alguns casos, por frustrar o aluno (ALCIDES; MARIA LÚCIA, 2006).

De acordo com o Instituto Nacional de Pesquisas Educacionais Anísio Teixeira - INEP - em uma avaliação da trajetória dos alunos de 2010 e 2014 divulgada pelo censo de 2015 , por exemplo, cerca de $11,4 \%$ dos alunos abandonaram os cursos nos quais haviam sido admitidos no ano de 2010, enquanto que esse número chegou a $49 \%$ em 2014, ou seja, houve aumento de 37,6\% no número de evadidos no decorrer de quatro anos (BRASIL, 2016).

O ministro da educação Mendonça Filho (2017) afirma que apesar de existirem mais de 8 milhões de vagas disponíveis para que se possa adentrar em um curso de ensino superior, apenas $42,1 \%$ destas estão preenchidas e somente $13,5 \%$ das vagas remanescentes foram ocupadas, o que indica pouca eficiência do sistema. Em conformidade com as projeções feitas em âmbito nacional pela Assessoria Econômica do Sindicato das Mantenedoras do Ensino Superior - Semesp - houve uma queda de 5\% nas matrículas de alunos no ano 2016, no ano de 2017, as matrículas estabilizaram nesse mesmo patamar, ou seja, está ocorrendo um retrocesso na inserção de jovens no ensino superior (SEMESP, 2017).

É de se reconhecer que no intervalo entre o início do processo educacional, tido como a entrada do educando na instituição e o momento de sua saída, traduzida em sua formatura, uma série de fatos podem ocorrer. Muitos sucessos recompensam esforços desenvolvidos, muitos obstáculos surgem, dificultando em grau variável a trajetória do aluno e que, por vezes, acabam interferindo na continuidade do processo, ocasionando o desligamento da instituição ou do curso (VELOSO; ALMEIDA, 2002).

Diante desse cenário, abre-se um campo de análise que permite $o$ acompanhamento desse processo, explorando seus limites e potencialidades. Se houve progressos na ampliação do acesso ao ensino superior, a permanência dos alunos nesse nível de ensino é ainda problemática, e um de seus indícios é o 
fenômeno da evasão escolar. Desta maneira, ocorreram mudanças nas formas de exclusão, pois, se antes ela se dava prioritariamente pela contenção no acesso, hoje, ela se faz no interior do sistema de ensino, nas características do próprio indivíduo e na sociedade onde estão inseridos.

Partindo dessa explanação, este trabalho teve como objetivo fazer um levantamento acerca de alguns dos fatores que podem levar os alunos do curso de graduação em administração de uma IES privada do Estado do Amazonas a evadir. Para isso foi levado em consideração a percepção dos discentes, dos professores e do coordenador do curso no que diz respeito ao assunto em tela.

\section{REFERENCIAL TEÓRICO}

\subsection{ENSINO SUPERIOR BRASILEIRO: HISTÓRIAS, CENÁRIOS E TENDÊNCIAS}

Visando compreender o vocábulo "educação", o dicionário de Língua Portuguesa Novo Aurélio (2010) traz na sua primeira acepção o significado de ato ou efeito de educar-se; em sua segunda acepção o significado consiste no processo de desenvolvimento da capacidade física, intelectual e moral da criança e do ser humano de forma geral, tencionando à sua melhor integração individual e social.

Mello Filho (1996 apud SILVA, 2014) coloca um conceito de educação mais compreensivo e abrangente diferenciando-o da mera instrução. Segundo o autor, a educação objetiva assegurar a formação necessária ao desenvolvimento de aptidões, das potencialidades e mesmo da personalidade do educando. Para ele, o processo educacional tem por meta: (a) habilitar o educando para o trabalho; (b) acondicionálo para o exercício consciente da cidadania.

A Constituição Federal de 1988 define que o termo "educação" refere-se a todos os processos da formação humana, a educação de uma maneira genérica abrange todos os processos formativos que se aprimora na vida familiar do indivíduo, na convivência humana, no trabalho, nos movimentos sociais e organizações da sociedade civil, envolve-se também nas manifestações culturais e nas instituições de ensino e pesquisa (Art. 205 e 227, CF/88). 
De acordo com Silva (2014, p. 20),

O ensino superior brasileiro começou muito timidamente com a vinda da Família Real para o Brasil em 1808. A rápida escala de 45 dias da Família Real em Salvador, Bahia, foi suficiente para que os comerciantes locais solicitassem a Dom João VI a abertura de uma universidade naquela cidade. Para tal, estavam dispostos a ajudar com boa quantia de recursos. Os comerciantes baianos não conseguiram convencer D. João VI a criar uma universidade naquela cidade, entretanto, conseguiram do monarca a abertura de Escolas de Cirurgia, Anatomia e Obstetrícia, instalações que atualmente abrigam a Faculdade de Medicina da Universidade Federal da Bahia.

Nessa mesma época foram criados o Museu Nacional, a Biblioteca Nacional e o Jardim Botânico. Como se pode perceber o Brasil já estava começando a se preparar culturalmente para receber as primeiras instituições de ensino superior. No entanto, entre a transmigração da família real, que nos trouxe a criação dos cursos médicos em 1808, e a formulação final da ideia de universidade, transcorreram-se mais de um século e meio para que pudesse ocorrer (SILVA, 2014).

Segundo Dourado (2011), embora a educação superior no Brasil tenha sido institucionalizada somente na década de 1920, referencia-se que entre as décadas de 1950 a 1960, a educação superior foi marcada pela federalização de IES e pela criação de universidades públicas federais.

Este foi o legado histórico da complexa reforma pela qual passou o ensino superior brasileiro, efetivado no país pela lei ${ }^{\circ} 5.540$ de 28 de novembro de 1968 (Lei da Reforma Universitária), posteriormente revogada pela lei $\mathrm{n}^{0} 9.394$ de 20 dezembro de 1996 - que preconizou o ideário universitário - pela edição de atos institucionais e pela fixação de políticas e de normas educacionais do ensino superior.

Atualmente, a educação superior brasileira é regida pelo Sistema Nacional de Avaliação da Educação Superior (Sinaes), criado pela lei 10.861, de 14 de abril de 2004. O Sinaes compreende a avaliação das instituições, dos cursos e do desempenho dos estudantes. São avaliados todos os aspectos que giram em torno desses três eixos, principalmente o ensino, a pesquisa, a extensão, a responsabilidade social, o desempenho dos alunos, a gestão da instituição, o corpo docente e as instalações. 


\subsection{EVASÃO ESCOLAR}

O simples ingresso no ensino superior não garante o êxito educacional dos estudantes, uma vez que as características desse nível de ensino são bem diferentes das do ensino médio. Essa nova fase causa no alunado certa insegurança quanto ao que estar por vir e por vezes exige mudanças significativas de hábitos.

Certamente, a evasão escolar é um fenômeno complexo, comum no mundo contemporâneo, sendo um dos problemas que mais afligem as instituições de ensino superior. De acordo com Silva Filho et al. (2007), a evasão estudantil no ensino superior é um problema internacional que afeta o resultado dos sistemas educacionais e a busca de suas causas tem sido objeto de estudo de muitos trabalhos e pesquisas educacionais.

A evasão escolar é um problema internacional que atinge a Educação Brasileira e é caracterizado pelo abandono do aluno às atividades escolares. [...], enquanto no setor público torna-se um investimento sem o devido retorno, nas instituições particulares é um dos principais motivos da perda de recursos, que poderiam ser empregados na melhoria da qualidade de ensino [...] (STOFFEL; ZIZA, 2014, p. 1).

Santos Junior et al. (2014) relatam que ao partir do pressuposto de que um dos principais papéis das universidades e IES é o de qualificar o corpo discente, preparando-os para o exercício profissional com a devida competência que deve ser obtida durante o período no qual se encontram no sistema acadêmico e ainda levando em consideração que a prestação de contas do uso de recursos públicos é medida usual em sociedades democráticas e o uso de receitas de instituições privadas impacta diretamente em sua sustentabilidade financeira. Torna-se preocupante o fato de uma parcela de estudantes não concluírem seus cursos.

Silva Filho et al. (2007) afirmam que no setor privado cerca de $2 \%$ a $6 \%$ das receitas das instituições de ensino superior são despendidos com marketing visando atrair novos estudantes, no entanto, nada parecido é investido para manter os 
estudantes que já estão matriculados. Além do mais, raríssimas são as IES brasileiras que possuem algum programa institucional de combate à evasão com planejamento de ações, acompanhamento de resultados e coleta de experiências bem-sucedidas.

De acordo com Fritsch et al. (2015, p. 83),

O Estado tem desenvolvido políticas educacionais para a inclusão de alunos com poucas possibilidades de acesso às instituições privadas de educação superior. As estratégias, definidas no PNE (2014-2024), indicam a continuidade dos programas: o Programa Universidade para Todos (ProUni), que busca conceder bolsas de estudo integrais e parciais em cursos de graduação e sequenciais de formação específica; e o Fundo de Financiamento do Estudante do Ensino Superior (Fies), que oferece isenção ou pagamento de alguns tributos àquelas instituições de ensino que aderem aos programas fortalecendo, assim, o sistema privado no ensino superior.

De certa forma, a possibilidade de mais acesso, é certamente necessária, entretanto, não é suficiente para a manutenção dos alunos até a diplomação. A evasão no ensino superior causa perdas para todos os atores envolvidos, para o discente, por exemplo, este fator não é somente um problema social, é configurado como um problema econômico também. Uma vez que quanto mais cedo o aluno de uma faculdade se formar, mais cedo estará no mercado de trabalho, todavia, aquele aluno que abandona o curso, está retardando a sua inserção no mercado como um profissional com ensino superior, ou pior, está desistindo da busca por diplomação e por uma profissão mais bem remunerada (STOFFEL; ZIZA, 2014).

\subsubsection{Possíveis causas da evasão}

Buscando entender e explicar as possíveis causas e consequências da evasão no ensino superior, alguns estudiosos tais como Diogo et al. (2016) têm constatado a complexidade deste fenômeno. $\mathrm{O}$ estudo da evasão configura um campo que envolve várias áreas do conhecimento humano, pode envolver questões pedagógicas, psicológicas, sociais, políticas, econômicas, administrativas, entre outras.

Diogo et al. (2016, p.130) afirmam que, 
De maneira geral, é possível identificar dois grupos de fatores relacionados ao fenômeno: os externos à instituição, como vocação, aspectos socioeconômicos e problemas de ordem pessoal dos alunos; e os internos à instituição, como infraestrutura da IES, corpo docente e assistência sócio-educacional.

No que diz respeito aos fatores externos, existem as falhas na tomada de decisão em relação ao curso. Estas englobam alguns aspectos como a falta de orientação profissional, sendo este o principal deles, pois em alguns casos o aluno ingressa no curso sem conhecer a profissão e se desestimula quando nota que a carreira escolhida não the proporciona satisfação pessoal. (GEMAQUE; SOUZA, 2016).

No que tange aos fatores internos, a infraestrutura e outras características como a disponibilidade de equipamentos de informática, laboratórios de ensino, qualidade do espaço físico, bibliotecas, instalações e corpo docente institucional são alguns dos fatores que influenciam no desempenho dos alunos no que tange ao interesse educacional e ao rendimento escolar (BRASIL, 1997 apud GEMAQUE; SOUZA, 2016).

Com relação ao corpo docente e levando em consideração que os primeiros períodos dos cursos são os que causam maior impacto sobre o universitário, Bardagi (2007) aborda que a má atuação do professor contribui de certa forma para que o discente desista do curso. Na visão do autor, os docentes, principalmente destes períodos, deveriam desenvolver práticas metodológicas motivadoras, qualificadas e significativas a fim de estimular o acadêmico a criar vínculo com a instituição de ensino.

Tinto (1975 apud AMBIEL, 2015, p. 42) "entendia que a evasão do Ensino Superior seria uma atitude voluntária, motivada principalmente por desempenho acadêmico insatisfatório e da não integração social ao novo ambiente". Porém, diversos estudos detectaram causas bem diferentes. Platt Neto et al. (2008), por exemplo, afirmam que um dos fatores causadores da evasão é a necessidade do trabalho remunerado devido pelas carências econômicas.

Para Campos (2016), a falta de compatibilidade entre os horários dos cursos 
e do trabalho caracterizam uma realidade que deve ser enfrentada pelas IES buscando com isso soluções para o problema da evasão. Ainda na linha de pensamento deste autor,

A dificuldade de conciliar a jornada de trabalho e o horário escolar é fator de suma importância na decisão de abandonar a faculdade. Quando as obrigações profissionais entram em conflito com os compromissos dos estudos, são estes, na maioria das vezes, que são adiados (CAMPOS, 2016, p.18).

Nesta direção, Diogo et al (2016) enfatizam que a análise do (in)sucesso escolar e a permanência ou a evasão de um curso deve tomar como base uma lógica de corresponsabilização, integrando-se variáveis pessoais, variáveis dos professores e variáveis do próprio ambiente de aprendizagem.

\subsection{POSIÇÃO DO MEC PARA REDUZIR EVASÃO EM FACULDADES}

Logo após a divulgação do Censo de Educação Superior, que pela primeira vez traçou o perfil dos estudantes ao longo da graduação, o ministro da educação, Mendonça Filho (2017), reiterou que a reforma no ensino médio é fundamental para que os indicadores possam melhorar (BRASIL, 2016). A mudança é proposta pela medida provisória $\mathrm{n}^{\mathrm{0}} 746 / 2016$ e terá um impacto direto nos indicadores do ensino superior (Semesp, 2015).

Isso porque os dados referentes ao ano de 2015, divulgados pelo INEP revelaram crescimento elevado na taxa de desistência do curso de ingressos. Em uma avaliação da trajetória dos alunos de 2010 e 2014, por exemplo, 11,4\% dos alunos abandonaram os cursos nos quais foram admitidos no ano de 2010, enquanto que em 2014, esse número chegou a 49\%, ou seja, houve aumento de 37,6\% no número de evadidos no decorrer de quatro anos (BRASIL, 2016).

Ainda de acordo com Mendonça Filho (2017), a ausência de orientação vocacional ao longo do ensino médio é um dos agravantes para a desistência significativa de jovens que ingressam no ensino superior. De acordo com o censo divulgado pelo INEP em 2016, cerca de 8.033.574 estudantes estavam regularmente na educação superior, o número superava o de 2014 em cerca de 2,5\%, quando 
havia cerca de 7.839.765 matriculados (BRASIL, 2016).

Além do que, das 8 milhões de vagas disponíveis, 42,1\% estão preenchidas e destas somente $13,5 \%$ das vagas remanescentes foram ocupadas. As vagas remanescentes indicam pouca eficiência do sistema, a reforma do ensino médio proporcionaria a esses jovens a oportunidade de experienciar algumas trajetórias acadêmicas mais associadas a cursos e carreiras no ensino superior. A presidente do INEP, Maria Inês Fini, expôs que

A falta de interesse em ocupar as vagas amplamente oferecidas, tanto na rede pública quanto no particular, deve-se ao fato de o jovem não identificar, na sua vontade, uma perspectiva desse ou aquele curso. É preciso haver uma conexão entre a educação básica e a de nível médio para ampliar as oportunidades de acesso à educação superior (BRASIL, 2016).

O diretor executivo da Semesp, Rodrigo Capelato, informou que as matrículas em cursos presenciais no Brasil cresceram em 3\% no ano de 2015, entretanto houve queda de $8,7 \%$ no número de ingressantes, o que acaba por revelar um quadro de crise econômica. Conforme as projeções feitas em âmbito nacional pela assessoria econômica da Semesp, houve também queda de 5\% nas matrículas em 2016 e tudo indica que, em 2017, as matrículas irão estabilizar nesse patamar, ou seja, está ocorrendo um retrocesso na inserção de jovens no ensino superior (SEMESP, 2017).

\subsection{EVASÃO ESTUDANTIL NO ESTADO DO AMAZONAS}

De acordo com o mapa do ensino superior no Brasil, desenvolvido pela assessoria econômica da Semesp (2016), o Estado do Amazonas possuía no ano de 2014 uma população de 3,9 milhões de habitantes, hoje essa população está estimada em 4,002 milhões de habitantes. Além de ser formada por quatro mesorregiões o que totaliza 62 municípios.

Ainda nesse ano de 2014, houve aumento de 6\% nas matrículas em instituições da rede privada, somando 88,8 mil inscrições, contra 83,7 mil do ano anterior. Enquanto que na rede pública o índice teve queda de 3,4\% nas matrículas, obtendo 51,6 mil em 2014, contra 53,5 mil no ano anterior. 
No que se refere à evasão anual de alunos, nos cursos presenciais o índice chegou a ser de $23,4 \%$ na rede privada e 19,3\% na rede pública. Já nos cursos a distância (EaD), nesse mesmo período, o índice de evasão anual em rede privada foi de $35,5 \%$ enquanto que na rede pública foi de 11,4\%. (SEMESP, 2016).

Outro dado interessante e que deve ser levado em consideração revela que o Estado do Amazonas apresenta em torno de 358 mil empregados com carteira assinada com ensino médio completo e apenas 126 mil com ensino superior completo. A remuneração média por grau de instrução no Estado, para os profissionais com ensino superior completo, ficou em torno de 4,6 mil reais mensais em 2014.

\section{ASPECTOS METODOLÓGICOS}

A pesquisa fundamentou-se nos preceitos metodológicos da pesquisa quanti-qualitativa, caracterizando-se como uma pesquisa de campo. O campo de investigação foi o curso de graduação em administração de uma IES privada do Estado do Amazonas. As variáveis investigadas foram os ambientes internos e externos à instituição. Internos: o grau de satisfação com o curso, com a instituição, a infraestrutura e o corpo docente. Externos: vocação, aspectos socioeconômicos e problemas de ordem pessoal.

Para responder aos objetivos propostos, a coleta de dados aconteceu em dois momentos: $1^{\circ}$ momento - Identificação da situação acadêmica através de observação em sala de aula. A observação foi realizada com os discentes do curso que estavam partindo do primeiro para o segundo período letivo dos turnos matutino e noturno. Ao todo, somando os dois turnos, a instituição possuía aproximadamente 570 alunos regularmente matriculados, dos quais 130 estavam cursando o primeiro período.

Em um $2^{\circ}$ momento - Aplicação de questionários com alunos e entrevistas com professores e o coordenador do curso. Essa parte do levantamento de dados não contou com toda essa população de discentes, o estudo trabalhou com uma amostra por acessibilidade, uma parcela convenientemente selecionada da população. (MARCONI; LAKATOS, 2013). Essa amostra foi de 20\% do total de alunos 
matriculados no primeiro período do curso, ou seja, 26 alunos, para os quais foi aplicado um questionário com 29 perguntas fechadas. O corpo docente da instituição contava com 227 professores ativos, dos quais 20 ministravam aulas para o curso de administração. Para analisar a percepção dos professores foi realizada uma entrevista estruturada com 22 perguntas mistas a uma amostra aleatória de 20\% do corpo docente do curso, isto é, quatro professores. E uma entrevista semiestruturada com o coordenador do curso.

A técnica de análise do conteúdo das entrevistas foi feita de acordo com o estipulado por Bardin (2009). Na concepção deste autor, a análise do conteúdo enquanto método, torna-se um conjunto de técnicas de análise das comunicações que se vale de procedimentos sistemáticos e objetivos de descrição do conteúdo das mensagens.

Para a análise dos dados coletados por meio de questionários, foi utilizada a estatística descritiva. Na visão de Guedes et al. (2017), essa técnica tem o objetivo de sintetizar uma série de valores da mesma natureza, permitindo assim que se tenha uma visão global da variação desses valores que podem ser expostos por meio de gráficos, tabelas e quadros.

\section{APRESENTAÇÃO E ANÁLISE DOS RESULTADOS}

\subsection{DISCENTES}

Com base nos dados coletados por meio de questionários com uma amostra aleatória de $20 \%$ do total de 130 alunos matriculados no primeiro período do curso de graduação em administração dos turnos matutino e noturno, foram obtidas as seguintes informações como mostra a Tabela 1. 
Tabela 1. Informações pessoais e socioeconômicas

\begin{tabular}{ccc}
\hline DADOS & $\%$ & VARÍ́VEL \\
\hline Sexo & 53,8 & Mulheres \\
\hline Idade & 38,5 & Entre 18 e 21 anos \\
Estado civil & 73,1 & Solteiro \\
Se possui filhos & 61,5 & Não \\
Fonte de renda & 46,2 & Emprego com carteira assinada \\
Carga horária de trabalho & 46,2 & Trabalho em tempo integral -40 horas semanais ou \\
Renda familiar & 73,1 & mais \\
\hline
\end{tabular}

Fonte: Pesquisa de campo (2017)

De acordo com esses dados foi possível perceber que dos 26 alunos que participaram desse estudo, cerca de 53,8\% eram mulheres das quais 38,5\% tinham entre 18 e 21 anos, sendo também que 73,1\% possuía estado civil com status de solteiro e $61,5 \%$ delas não possuíam filhos. Além disso foi constatado que 46,2\% da população que participou do estudo é empregado com carteira assinada e trabalha em tempo integral, outro fator que deve ser levado em consideração é que $73,1 \%$ deles possuem renda familiar de até três salários mínimos $(\mathrm{R} \$ 2.811,00)$, ou seja, estão incluídos na classe social média.

No que se refere à instituição de ensino superior e ao curso estudado, os dados obtidos estão inseridos na Tabela 2.

Tabela 2. Sobre a IES

\begin{tabular}{lcc}
\hline \multicolumn{1}{c}{ DADOS } & $\%$ & VARIÁVEL \\
\hline Qual a principal razão para a escolha da IES? & 30,8 & Qualidade/reputação \\
A infraestrutura da IES atende as suas necessidades? & 73,1 & Atende totalmente \\
A escolha deste curso foi sua primeira opção? & 69,2 & Sim \\
Qual o principal motivo de você ter escolhido este curso? & 34,6 & Valorização \\
Como você classifica seu relacionamento com os professores & 46,2 & profissional \\
do curso? & Bom \\
Como você classifica a metodologia adotada pelo professor? & 38,5 & Ótimo \\
\hline
\end{tabular}

Fonte: Pesquisa de campo, 2017. 
Foi constatado que 30,8\% dos alunos escolheram a instituição por conta da sua qualidade/reputação e $73,1 \%$ mencionaram que a infraestrutura atende totalmente as suas necessidades. Cerca de $69,2 \%$ dos respondentes disseram que a escolha do curso em questão foi a sua primeira opção, sendo que 34,6\% admitem que escolheram este curso por valorização profissional, além de 46,2\% deles atestar que possuem bom relacionamento com os professores e 38,5\% afirmam que a metodologia de ensino adotada pelos professores é ótima, isto é, contribui de forma significativa para o aprendizado dos discentes em sala de aula.

Quando questionados sobre os fatores favoráveis à frequência ao curso, foram obtidas as seguintes respostas, como mostra o Gráfico 1:

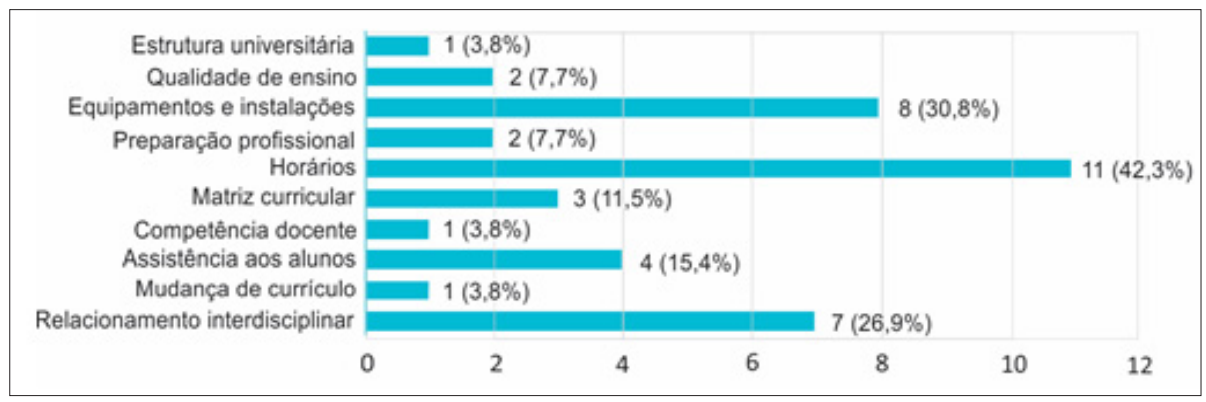

Gráfico 1. Fatores favoráveis à frequência ao curso Fonte: Pesquisa de campo, 2017.

Cerca de $42,3 \%$ dos discentes reconhecem que os horários dos cursos são os mais conflituosos, uma vez que os horários das aulas nos primeiros períodos possuem a grade completamente cheia levando em consideração que 46,2\% dos respondentes trabalham em tempo integral, isto é, 40 horas semanais ou mais, além disso, outro fator adverso à permanência no curso apontado por 30,8\% dos alunos é o de equipamentos e instalações para o ensino.

No quesito da evasão escolar no ensino superior, objetivo geral deste trabalho, foram obtidos os seguintes resultados ao questionar os discentes quanto à pretensão de dar continuidade ao curso, como consta no Gráfico 2. 


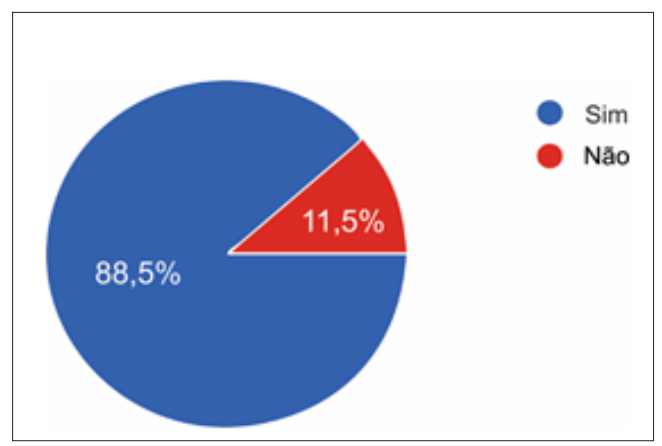

Gráfico 2. Índice de evasão escolar

Fonte: Pesquisa de campo, 2017.

Foi possível constatar que $88,5 \%$ dos discentes pretendem dar continuidade ao curso, mesmo que apenas 69,2\% destes o tenham escolhido como primeira opção. Um fator preocupante e que requer bastante atenção é que 11,5\% da população participante do estudo não pretende dar continuidade ao curso, quando questionados sobre o assunto, os mesmos afirmaram que este não tinha sido a sua primeira opção, o que de fato foi confirmando durante a análise dos questionários.

Portanto, no que se refere aos discentes, foi possível perceber que apesar de existirem fatores na instituição que não eram favoráveis à permanência no curso, estes não eram os responsáveis pela evasão, na verdade os discentes estavam sujeitos a evadir por este não ser o curso desejado e pelo mesmo não ter atendido às suas expectativas, ou seja, a origem da evasão nessa instituição é de natureza externa.

Esse dado fortalece a tese de Gaioso (2006) e Diogo et al. (2016) ao afirmarem que a evasão discente pode ocorrer por causas internas ou externas à instituição, existindo nas causas externas a falha na tomada de decisão em relação ao curso e o desconhecimento de sua metodologia. Esta variável engloba alguns aspectos como a falta de orientação profissional, sendo este o principal deles, pois em alguns casos o aluno ingressa no curso sem conhecer a profissão e se desestimula quando nota que a carreira escolhida não the proporciona satisfação pessoal. 


\subsection{DOCENTES}

Baseado na entrevista estruturada respondida por $20 \%$ do total de 20 professores que ministram aulas para o curso estudado foi possível constatar que para $25 \%$ dos professores entrevistados a dificuldade em acompanhar o desenvolvimento do curso por conta da deficiência na educação básica e o desconhecimento prévio do curso são fatores que contribuem de forma significativa para a evasão escolar. $\mathrm{O}$ que reafirma a colocação de Biazus (2004), ao afirmar que as principais causas da evasão são fatores de ordem pessoal e que fogem ao controle da instituição.

Outro dado interessante é que 50\% dos professores acreditam que a evasão escolar na educação superior também pode ser causada por conta da escolha equivocada do curso ou o fato do mesmo não ter correspondido às expectativas do discente, além de defenderem a ideia de que a falta de associação entre a teoria e prática nas disciplinas é outro fator que contribui de maneira significativa.

Por outro lado, é importante levar outros fatores em consideração, uma vez que podem influenciar de maneira significativa na decisão dos discentes em dar continuidade ao curso ou não, são eles: a dificuldade financeira momentânea e a falta de um financiamento mais amplo aos alunos carentes, na qual $75 \%$ dos professores que participaram da pesquisa acreditam serem fatores de extrema influência no quesito da evasão.

A possiblidade de mais acesso à educação, segundo Fritsch et al. (2015), vem sendo desenvolvida pelo Estado. De acordo com o autor, o Estado vem desenvolvendo políticas educacionais para a inclusão de alunos com poucas possibilidades de acesso às instituições privadas de educação superior. As estratégias, definidas no PNE (2014-2024), indicam a continuidade dos programas: o Programa Universidade para Todos (ProUni) e o Fundo de Financiamento do Estudante do Ensino Superior (Fies), fortalecendo, assim, o sistema privado no ensino superior.

Cerca de 50\% dos entrevistados presumem que a incompatibilidade entre os horários da jornada de trabalho e as disponíveis para o curso presencial são fatores que contribuem pouco para evasão, enquanto que $25 \%$ deles acreditam que esta é uma causa que pode contribuir totalmente. O que contradiz a afirmação de Gaioso (2006) que ao entrevistar dirigentes e estudantes apontou que um dos principais 
fatores relacionados à evasão no ensino superior são problemas financeiros não planejados pelo discente e horário de trabalho incompatível com o de estudo.

Quando questionados a respeito de sua metodologia de ensino, 100\% dos professores asseveraram que a mesma é totalmente adequada para o ensinoaprendizagem do discente, ao ser indagado o porquê disso o entrevistado 1, por exemplo, respondeu: "porque procuro adequar a teoria e a prática e também trabalbo muitos exercícios em sala de aula", ao passo que o entrevistado 2 respondeu: "procuro fazer a associação entre a teoria e a prática".

Esse dado foi confirmado por apenas 38,5\% do total de discentes que participaram deste estudo. Biazus (2004), ressalta um dos fatores causadores da evasão é o processo resultante do descontentamento acerca dos métodos didáticos pedagógicos do corpo docente ou da infraestrutura da universidade.

É importante destacar que nesta pesquisa não foi constatado que a evasão estava sujeita a ocorrer por falta de um financiamento e apoio mais amplo aos estudantes, entretanto, é necessário mais investimento nessa parte visando possibilitar o ingresso e permanência de mais discentes no ensino superior.

\subsection{COORDENADOR}

Na entrevista realizada com o coordenador do curso de administração, prof. MSc. Elton Pereira Teixeira, foi possível analisar a evasão discente mais voltada pela ótica da gestão. Na visão do coordenador, fatores como desconhecimento prévio do curso, dificuldade em acompanhar o desenvolvimento do curso por conta da deficiência na educação básica, infraestrutura da instituição, necessidade de trabalho remunerado, problemas familiares e falta de associação entre teoria e prática nas disciplinas são fatores muito relativos e de pouca influência na questão da evasão discente.

Para ele, os fatores que contribuem de maneira significativa para a evasão discente no ensino superior são a dificuldade financeira momentânea e a falta de financiamento mais amplo aos alunos carentes, dado que a primeira variável é um fator que foge ao controle do discente e influencia fortemente em sua tomada de decisão e a segunda fica a critério da instituição oferecer, o que condiz com o 
explanado por Gaioso (2006) e Ribeiro (2005) que verificaram grande número de prováveis fatores influenciadores para a evasão universitária, contendo questões de ordens financeiras e a possiblidade de mais acesso ao meio educacional.

Nas questões mais voltadas para a gestão do curso, o coordenador ressaltou que "procura promover a integração dos alunos novatos por meio de visita orientada, no primeiro dia os discentes têm contato com os subsequentes do coordenador, há também a formação de grupos de trabalhos quando os discentes ingressam no primeiro período no segundo semestre letivo".

O coordenador ressaltou também que a gestão acadêmica possui controles sistemáticos que visam controlar a evasão discente, esses controles são passados aos coordenadores de curso e posteriormente passados aos professores que são treinados e orientados a acompanhar bem os alunos para não haver evasão, segundo ele a coordenação usa o "contato e acompanhamento dos alunos todos os semestres" como uma medida preventiva.

Quando questionado sobre que fatores poderiam a vir melhorar além dos já citados anteriormente para que a evasão discente viesse a ser minimizada, o coordenador respondeu: "acompanhar e manter o controle sobre cada turma regularmente identificando onde estão os problemas e os solucionando da melhor maneira possível".

O que reafirma a visão de Santos Junior (2014), que diz que há IES que buscam minimizar a evasão com programas institucionais que visem à integração pessoal, social e acadêmica dos alunos. De acordo com ele, existem políticas voltadas para a permanência dos estudantes nas IES, como o fortalecimento de medidas que privilegiam o apoio financeiro e psicológico aos alunos carentes ou a modernização de métodos e de currículos.

\section{CONCLUSÃO}

Sabendo que a evasão no ensino superior é um problema internacional que interfere de forma direta nos resultados dos sistemas educacionais e que a perda de discentes que iniciam seus cursos e não os concluem são considerados desperdícios 
sociais, acadêmicos e econômicos, é possível afirmar que a evasão não pode ser solucionada com ações generalistas e focalizadas a apenas uma variável, visto que este é um processo complexo e está relacionado a diversos fatores intervenientes, mesmo que seja aspecto preponderante, considerando a alteração no perfil dos estudantes universitários nos últimos anos (RISTOFF, 2013).

Neste estudo, foi possível concluir que o índice de evasão poderá chegar a 11,5\% no curso de administração da instituição objeto desse estudo. Além disso, no que se refere aos discentes foi possível constatar que mesmo que $73,1 \%$ dos alunos considerarem que existem fatores não favoráveis à frequência ao curso, tais como os horários e os equipamentos e instalações, estes fatores não eram os responsáveis pela evasão, na verdade os discentes estavam sujeitos a evasão por este não ser o curso desejado e pelo mesmo não ter atendido às suas expectativas, ou seja, a origem da evasão nessa instituição é de natureza externa.

Ao analisar a percepção dos professores com relação ao assunto, foi possível perceber que $50 \%$ deles acreditavam que a evasão discente era causada pela escolha equivocada de curso ou o fato de o mesmo não ter correspondido às expectativas dos discentes e neste ponto estavam certos, com base na análise dos dados coletados com os mesmos. Entretanto, $75 \%$ dos professores e o próprio coordenador do curso acreditavam que outros fatores como a dificuldade financeira momentânea e falta de financiamento mais amplo aos alunos carentes fossem os principais responsáveis pela evasão. Todavia, isso não foi confirmado ao analisar os dados coletados com os discentes.

De acordo com o coordenador do curso, a instituição possui controles sistemáticos que visam combater a evasão discente, estes controles são repassados aos coordenadores de cursos e posteriormente repassados aos professores. Além disso, os alunos são acompanhados pelo coordenador e seus subsequentes durante o desenvolvimento do curso semestralmente,

Em virtude dos fatos mencionados, foi possível constatar que o modelo de gestão das IES foi desenvolvido a princípio para a captação, e não para retenção de alunos, tendo em vista que, historicamente, a demanda vinha superando a oferta. A perda de alunos ainda é tratada em muitos casos como uma decorrência natural, sendo aceitável, dentro das instituições, que os alunos sem condições - acadêmicas, 
financeiras ou psicológicas - não concluam o ensino superior (ALCIDES; MARIA LÚCIA, 2006). No entanto, já possuem IES que se preocupam e investem em soluções para minimizar o problema.

Outro fator que deve ser levado em consideração é o que está instruído no artigo 206 da CF/88, no qual diz que "o ensino será ministrado com base nos seguintes princípios: I - igualdade de condições para o acesso e permanência a escola... VII garantia de padrão de qualidade”. Na ótica de Silva (2014), a instituição educacional tem a responsabilidade de oferecer ensino de qualidade aos seus alunos. Não se pode somente redigir sua missão declarando como um compromisso oferecer ensino de qualidade, isto é, a instituição deve praticar essa missão rigorosamente, de modo que a missão escrita e a prática sejam idênticas.

A missão escrita não deve ser somente uma peça de retórica como se pode observar em muitas instituições de ensino que apregoam ensino de primeira classe, entretanto, não praticam o teor semântico das suas missões. Ainda de acordo com Silva (2014, p. 90),

A instituição de ensino deverá estar preparada para acolher esse aluno, avaliar os seus conhecimentos básicos e suprir as suas deficiências por meios de aulas especiais, a fim de recuperar o conteúdo que esse aluno deixou de adquirir, tanto no ensino fundamental, quanto no ensino médio. Desse modo, a instituição cumpre o dispositivo constitucional, oferencendo a todos seus alunos as mesmas condições de parmanência na instituição.

Portanto, para que a gestão acadêmica tenha bom rendimento dos seus alunos e possua controle sobre o índice de evasão em seus cursos, a mesma deve analisar a instituição como um todo, todos os aspectos internos e externos a ela, como a estrutura física, as falhas existentes no curso, a entidade educacional, horários, matriz curricular e até mesmo fatores como desconhecimento prévio do curso pelos discentes, dificuldade na educação básica e no desenvolver do curso a própria motivação dos discentes.

Os objetivos previstos para esta pesquisa foram alcançados. Por oportuno, ressalta-se a importância de se fazerem estudos mais consistentes que primem pelo viés da permanência ao analisar a evasão e/ou o abandono discente na educação superior, para que assim possam ser levantadas possibilidades de mudança e de 
qualificação do acesso, permanência e conclusão dos estudos em instituições de ensino superior.

\section{REFERÊNCIAS}

ALCIDES, F. S.; MARIA LÚCIA, B. A evasão escolar em uma universidade privada. Ensino em Engenharia: empreender e preservar. In: COBENGE, 34., 2006, Passo Fundo. Anais... Passo Fundo: Ed. da Universidade de Passo Fundo, 2006.

AMBIEL, R. A. M. Construção da Escala de Motivos para Evasão do Ensino Superior. Aval. psicol., v. 14, n. 1, p. 41-52, abr. 2015.

BARDAGI, M. P. Evasão e comportamento vocacional de universitários: estudos sobre o desenvolvimento de carreira na graduação. Programas de Pós-graduação da CAPES. 2007. Disponível em: < http:/hdl.handle.net/10183/10762> . Acesso em: 10 jun. 2017.

BARDIN, L. Análise de Conteúdo. Lisboa, Portugal; Edições 70, 2009.

BIAZUS, C. A. Sistema de fatores que influenciam o aluno a evadir-se dos cursos de graduação na UFSM e na UFSC: um estudo no curso de ciências contábeis. 2004. 203f. Tese (Doutorado) - Universidade Federal de Santa Catarina, Florianópolis-SC, 2004.

BRASIL. Constituição (1988). Constituição da República Federativa do Brasil. Constituição da República Federativa do Brasil: texto constitucional promulgado em 5 de outubro de 1988, com as alterações determinadas pelas Emendas Constitucionais de Revisão nos 1 a 6/94, pelas Emendas Constitucionais nos 1/92 a 91/2016 e pelo Decreto Legislativo no 186/2008. Brasília: Senado Federal, Coordenação de Edições Técnicas, 2016. 124-133 p.

BRASIL. MEC defende reformas para reduzir evasão em faculdades. Disponível em: $\quad$ <http://www.brasil.gov.br/educacao/2016/10/mec-defende-reformas-parareduzir-evasao-em-faculdades > . Acesso em: 10 de abril de 2017. 
CAMPOS, J. D. S. Fatores explicativos para a evasão no ensino superior através da análise de sobrevivência: o caso da UFPE. 2016. 97f. Dissertação (Mestrado em Engenharia da Produção) - Universidade Federal de Pernambuco, Recife, 2016.

DIOGO, M. F. et al. Percepções de coordenadores de curso superior sobre evasão, reprovações e estratégias preventivas. Avaliação, v. 21, n. 1, p. 125-151, mar. 2016. DOURADO, L. F. O público e o privado na agenda educacional brasileira. In: AGUIAR, M. A.; FERREIRA, N. S. C. (Org.). Gestão da educação: impasses, perspectivas e compromissos. São Paulo: Cortez, 2011.

FERREIRA, A. B. H. Dicionário Aurélio da Língua Portuguesa. 5. ed. Curitiba: Positivo, 2010, p. 2272.

FRITSCH, R. et al. A evasão nos cursos de graduação em uma instituição de ensino superior privada. Universidade do Vale do Rio dos Sinos. Revista Educação em Questão, Natal, v. 52, n. 38, p. 81-108, maio/ago. 2015.

GAIOSO, N. P. L. O fenômeno da evasão escolar na educação superior no Brasil. Unesco, 2006. Disponível em: <www.iesalc.unesco.org.ve/programas/ Deserción/Informe > . Acesso em: 26 outubro 2017.

GEMAQUE, L. S. B.; SOUZA, L. G. Diplomação, Retenção e Evasão: estudo com enfoque na evasão dos cursos de graduação na Universidade Federal do Maranhão no período de 2008 a 2010. Ensino \& Multidisciplinaridade, São Luís, v. 2, n. 1, p. 84-105, jan.jjun. 2016.

GUEDES, T. A. et al. Projeto de Ensino: Aprender fazendo estatística. Disponível em $<$ http://www.each.usp.br/rvicente/Guedes_etal_Estatistica_Descritiva.pdf $>$. Acesso em: 21 de novembro de 2017.

MARCONI, M. A.; LAKATOS, E. M. Técnicas de pesquisa. 7. ed. São Paulo: Atlas, 2013.

PLATT NETO, O. A. et al. Utilização de metas de desempenho ligadas à taxa de evasão escolar nas universidades públicas. Revista de Educação e pesquisa em Contabilidade. Brasília, v. 2, art. 4, p. 54-74. maio/ago. 2008. 
RIBEIRO, M. A. O Projeto Profissional Familiar como Determinante da Evasão Universitária: um estudo preliminar. Revista Brasileira de Orientação Profissional, v. 6, n. 2, 2005.

RISTOFF, D. Perfil socioeconômico do estudante de graduação: uma análise de dois ciclos completos do ENADE (2004 a 2009). Rio de Janeiro: FLACSO: GEA: UERJ, 2013. (Cadernos do GEA, no 4 ).

SANTOS JUNIOR, J. S. et al. Aprimoramento da gestão acadêmica: intervenções e alternativas para controle da evasão estudantil. 2014 dez. 03-05. In: COLÓQUIO INTERNACIONAL DE GESTÃO UNIVERSITÁRIA - CIGU, 19., 2014, Florianópolis. Anais... Florianópolis, 2014.

SEMESP. Mapa do ensino superior. Estado do Amazonas. p. 165-170. Disponível em: < http://convergenciacom.net/pdf/mapa-ensino-superior-brasil-2015.pdf>. Acesso em: 13 maio 2017.

SEMESP. Mapa do ensino superior. Estado do Amazonas. p. 161-168. Disponível em: < http://convergenciacom.net/pdf/mapa_ensino_superior_2016.pdf $>$. Acesso em: 13 maio 2017.

SEMESP. Semesp divulga queda de 3,3\% de matrículas nos cursos presenciais na rede privada em Ribeirão Preto. Disponível em: < http://www.semesp.org. br/site/semesp-divulga-queda-de-33-de-matriculas-nos-cursos-presenciais-na-redeprivada-em-ribeirao-preto/> . Acesso em: 13 maio 2017.

SILVA, A. S. Retenção ou evasão: a grande questão social das instituições de ensino superior. 2014. 121f. Dissertação (Mestrado em Direito Político e Econômico) - Universidade Presbiteriana Mackenzie, São Paulo, 2014.

SILVA FILHO, R. L. L. et al. A evasão no ensino superior brasileiro. Instituto Lobo para o Desenvolvimento da Educação, da Ciência e da Tecnologia. Cadernos de Pesquisa, v. 37, n. 132, p. 641,659, set./dez. 2007.

STOFFEL, W. P.; ZIZA, C. R. Evasão Escolar em Cursos Superiores: estudo comparativo entre os pedidos de trancamento e o aproveitamento escolar. In: 
SIMPÓSIO PEDAGÓGICO E PESQUISAS EM COMUNICAÇÃO - SIMPED, 9., 2014. Anais... 2014. p. 11.

VELOSO, T. C. M. A.; ALMEIDA, E. P. Evasão nos cursos de graduação da universidade federal de Mato Grosso, campus universitário de Cuiabá: um processo de exclusão. Série-Estudos, Periódico do Mestrado em Educação da UCDB, Campo Grande, n. 13, p. 133-148, jan./jun. 2002.

Recebido em: 05/03/2018 Aceito em: 26/09/2018 